\title{
SALURAN DAN MARGIN PEMASARAN KOPI CAP LERENG TANCAK KEMBAR DI DESA ANDUNGSARI KECAMATAN PAKEM KABUPATEN BONDOWOSO
}

\author{
*Dinda Dara Ardila, Titin Agustina, Sri Subekti \\ Program Studi Agribisnis, Fakultas Pertanian, Universitas Jember \\ *Corresponding author: dindadaraardila1414@gmail.com
}

\begin{abstract}
Arabica and robusta coffees as the agricultural commodities are cultivated in Pakem sub-district, Bondowoso regency. One of the companies processing arabica and robusta coffees in Bondowoso is Lereng Tancak Kembar agroindustry. However, the agroindustry often experiences some obstacles to market its products because road access to the area is quite difficult, so the condition increases transportation costs. Therefore, it is necessary to know about the marketing channel of Lereng Tancak Kembar, so it affects the price and margin of coffee marketing to the last consumers. The reserach area was determined purposively. Descriptive data analysis was used to analyze the coffee marketing channel, and marketing margin analysis was used to know the coffee marketing margin. The findings indicated that: (1) the marketing of Lereng Tancak Kembar coffee had four marketing channels, consisting of two Arabica coffee marketing channels and two robusta coffee marketing channels. The first marketing channel of arabica coffee included: agroindustry - sales - retailers consumers. The second marketing channel included: agroindustry - retailers consumers. The first marketing channel of robusta coffee included: agro-industry sales - retailers - consumers. The second marketing channels of robusta coffees included: agroindustry - retailers - consumers. (2) the marketing margin for the first channel of arabica coffee was Rp. 86,660.00, and the second channel was Rp. 53,330.00. The marketing margin for the first channel of robusta coffee was $R p$. 100,000.00, and the second channel was Rp. 85,000.00.
\end{abstract}

Keywords: coffee, marketing channels, and marketing margin

\begin{abstract}
Abstrak: Kopi arabika dan kopi robusta merupakan komoditas pertanian yang banyak dibudidayakan di Kecamatan Pakem Kabupaten Bondowoso. Salah satu perusahaan yang mengolah kopi arabika dan kopi robusta di daerah tersebut adalah agroindustri Lereng Tancak Kembar. Namun agroindustri tersebut sering mengalami hambatan untuk memasarkan produknya dikarenakan akses jalan ke daerah tersebut cukup sulit sehingga meningkatkan biaya transportasi, maka perlu diketahui bagaimana saluran pemasaran kopi cap Lereng Tancak Kembar, sehingga akan mempengaruh terhadap harga dan margin pemasaran kopi pada konsumen akhir. Penentuan daerah penelitian menggunakan metode secara sengaja. Analisis data secara diskriptif digunakan untuk menganalisis saluran pemasaran kopi, dan analisis margin pemasaran digunakan untuk mengetahui margin pemasaran kopi. Hasil analisis menunjukkan bahwa: (1) pemasaran kopi cap Lereng Tancak Kembar memiliki empat saluran pemasaran, terdiri dari dua saluran pemasaran kopi arabika dan dua saluran pemasaran kopi robusta. Saluran pemasaran 1 kopi arabika meliputi: agroindustri - sales - pedagang pengecer - konsumen akhir. Saluran pemasaran 2 kopi arabika meliputi: agroindustri pedagang pengecer - konsumen akhir. Saluran pemasaran 1 kopi robusta meliputi: agroindustri - sales - pedagang pengecer - konsumen akhir. Saluran pemasaran 2 kopi robusta meliputi: agroindustri - pedagang pengecer - konsumen akhir, (2) margin pemasaran kopi arabika saluran 1 sebesar Rp. 86.660,00, dan saluran 2 sebesar Rp.
\end{abstract}


Dinda Dara A., Titin A., Sri Subekti: Saluran dan Margin Pemasaran Kopi...

53.330,00, serta margin pemasaran kopi robusta saluran 1 sebesar Rp. 100.000,00, dan saluran 2 sebesar Rp. 85.000,00.

Kata Kunci: kopi, saluran pemasaran, margin pemasaran

\section{PENDAHULUAN}

Kopi merupakan salah satu komoditas perkebunan yang mulai banyak diminati oleh masyarakat Indonesia. Terdapat banyak jenis dari kopi di dunia yang memiliki kualitas dan mutu terbaik. Hal tersebut yang menjadikan jenis kopi tertentu begitu digemari dan dicari oleh banyak penikmat kopi di seluruh dunia. Jenis Kopi arabika dan robusta adalah beberapa jenis kopi yang banyak digemari. Kopi arabika memiliki rasa mulai dari manis, lembut, hingga rasanya yang kuat dan tajam. Sedangkan kopi robusta memiliki variasi rasa netral hingga tajam dan sering dianggap memiliki rasa seperti gandum (Rahardjo, 2012).

Seiring dengan banyaknya peminat kopi, maka perlu adanya suatu pengolahan terhadap kopi tersebut. Hal itu dikarenakan kopi yang dapat dinikmati bukannya kopi yang baru dilakukan proses pemanenan. Terkait hal tersebut, diperlukan suatu perusahaan yang bisa mengolah biji kopi menjadi bubuk kopi yang siap untuk dikonsumsi. Perusahaan yang dimaksud adalah agroindustri kopi. Agroindustri dapat diartikan dua hal, yaitu: (1) agroindustri adalah industri yang mengolah bahan baku utama dari produk pertanian dengan memanajemen pengolahan makanan dalam suatu perusahaan produk olahan, dimana penggunaan bahan baku minimal 20\% dari jumlah bahan baku yang digunakan adalah pertanian; (2) agroindustri adalah tahapan pembangunan lanjutan dari pembangunan pertanian, namun dilakukan ketika sebelum tahapan pembangunan industri (Soekartawi, 2001).

Sebelum dipasarkan, kopi terlebih dahulu dilakukan pengolahan agar memiliki nilai lebih dibandingkan dengan biji kopi yang baru selesai dilakukan pemanenan. Pengolahan tersebut bertujuan agar kopi lebih mudah untuk dipasarkan serta mendapatkan tambahan keuntungan bagi lembaga yang mengusahakannnya. Salah satu agroindustri yang melakukan pengolahan kopi arabika dan kopi robusta adalah Agroindustri Lereng Tancak Kembar yang terletak di Desa
Andungsari Kecamatan Pakem Kabupaten Bondowoso. Proses pengolahan kopi dilakukan guna memenuhi permintaan konsumen akan produk kopi yang berkualitas dan mudah untuk dikonsumsi dari pada kopi yang baru dilakukan pemanenan.

Produk yang dihasilkan oleh agroindustri tersebut dipasarkan ke wilayah-wilayah yang ada di Kabupaten Bondowoso. Namun disisi lain dalam proses pendistribusian produk agroindustri tersebut memiliki beberapa permasalahan, diantaranya adalah lokasi yang terpencil di daerah pegunungan serta akses ke lokasi agroindustri yang sangat sulit dengan jalan bebatuan yang sangat beresiko jika sering dilalui oleh kendaraan bermotor. Menurut pemilik agroindustri, kedua permasalahan tersebut sangat berdampak negatif terhadap penjualan pada agroindustri kopi miliknya. Seringkali para pembeli mengeluh karena akses ke lokasi agroindustri sangat sulit sehingga mereka cenderung tidak melakukan pemesanan kembali. Dampak lain yang ditimbulkan dari permasalahan tersebut adalah meningkatnya biaya tranportasi, sehingga akan berpengaruh terhadap harga dan marjin pemasaran kopi hingga pada konsumen akhir.

Kegiatan-kegiatan yang dilakukan oleh agroindustri kopi seperti penjualan produk kepada tengkulak serta kegiatan lembaga lainnya dalam memasarkan produk kopi akan memunculkan saluran pemasaran. Dalam rangka memenuhi permintaan akan produk tersebut pemasaran didalamnya termasuk seluruh proses dan kegiatan yang terlibat didalam penyampaian produk sampai ke tangan pemakai atau konsumen. Semua itu termasuk proses produksi pada manufaktur, sistem transportasi yang menggerakkan produk dari manufaktur sampai ke pedagang pengecer (Wuwung, 2013).

Sugiarti (2010) mengatakan bahwa kegiatan pemasaran kopi adalah suatu rangkaian kegiatan yang menyalurkan kopi beserta hasil olahannya, mulai dari petani produsen sampai kepada konsumen. Proses pemasaran kopi yang tidak efisien disebabkan karena penyebaran marjin, biaya dan 
keuntungan pada tiap tingkat lembaga pemasaran kurang merata. Seperti yang terjadi pada Pemasaran Kopi di Kecamatan Bermani Ulu Raya Kabupaten Rejang Lebong. Pada proses pemasaran kopi di daerah tersebut, marjin pemasaran terbesar terdapat pada pedagang besar yaitu $\mathrm{Rp} 16.750$ per $\mathrm{Kg}$ atau $55,83 \%$ dari harga eceran. Besarnya marjin pada tingkat lembaga ini disebabkan oleh tingginya keuntungan yang diperoleh yaitu sebesar $13.815,87$ atau $46,06 \%$ dari harga eceran.

Kegiatan pemasaran tidak lepas dari keberadaan lembaga pemasaran yang terdapat didalamnya dan saling terkait satu sama lain. Kegiatan yang dilakukan dapat berupa penyaluran barang, pengolahan barang maupun pengaturan-pengaturan lainnya baik itu pengaturan harga dan komunikasi. Kegiatan tersebut dilakukan agar keuntungan dapat diraih oleh lembaga yang menjadi penyusun saluran pemasaran. Selain itu penelitian ini bertujuan untuk mengetahui saluran pemasaran kopi cap Lereng Tancak Kembar, dan juga untuk mengetahui marjin pemasaran pada masing-masing saluran pemasaran kopi cap Lereng Tancak Kembar di Desa Andungsari Kecamatan Pakem Kabupaten Bondowoso. Berdasarkan seluruh latar belakang tersebut maka nantinya diharapkan semua lembaga pemasaran penyusun saluran pemasaran kopi Cap Lereng Tancak Kembar dapat memilih saluran pemasaran yang paling tepat agar memberikan keuntungan yang lebih besar bagi lembaga-lembaga yang mengusahakannya.

\section{METODE PENELITIAN}

Penentuan daerah penelitian dilakukan dengan secara sengaja (purposive method). Daerah yang dimaksud adalah Kecamatan Pakem Kabupaten Bondowoso. Pemilihan tempat tersebut dikarenakan Kecamatan Pakem masuk dalam tiga besar daerah dengan produksi kopi tertinggi di Kabupaten Bondowoso. Menurut data dari Badan Pusat Statistik Kabupaten Bondowoso tahun 2016 produksi kopi di Kecamatan Pakem pada tahun 2015 adalah sebesar 24,50 ton, atau yang tertinggi kedua di Kabupaten Bondowoso. Kopi di Kecamatan Pakem diolah menjadi produk olahan berupa kopi bubuk. Kopi bubuk tersebut di produksi oleh agroindustri kopi Lereng Tancak Kembar yang ada di Desa Andungsari Kecamatan Pakem Kabupaten Bondowoso.

Metode yang digunakan dalam penelitian ini adalah menggunakan dua metode, yaitu deskriptif dan analitik. Metode diskriptif adalah suatu metode dalam meneliti status sekelompok manusia, suatu objek, suatu set kondisi, suatu sistem pemikiran, ataupun suatu kelas peristiwa pada masa sekarang. Tujuan dari penelitian deskriptif ini adalah untuk membuat diskripsi, gambaran atau lukisan secara sistematis, faktual dan akurat mengenai fakta-fakta, sifatsifat serta hubungan antarfenomena yang diselidiki. Metode penelitian analitik yaitu berfungsi menguji hipotesa-hipotesa dan mengadakan interpretasi terhadap hasil analisa (Nazir, 2014).

Metode pengumpulan data dilakukan dengan menggunakan teknik observasi, wawancara, dan dokumentasi. Metode pengambilan contoh dalam penelitian ini menggunakan metode purposive sampling dan snowball sampling. Analisis diskriptif digunakan untuk mengetahui Saluran pemasaran kopi cap Lereng Tancak Kembar pada agroindustri kopi Lereng Tancak Kembar. Analisis diskriptif tersebut didapatkan dengan cara melakukan wawancara kepada repsonden mengenai saluran pemasaran kopi di daerah tersebut. Responden yang dimaksud adalah lembaga-lembaga pemasaran kopi yang terdiri dari agroindustri, sales, dan juga pedagang pengecer kopi. Kemudian hasil wawancara tersebut didiskripsikan untuk menjelaskan gambaran tentang saluran pemasaran kopi cap Lereng Tancak Kembar di agroindustri kopi Lereng Tancak Kembar.

Soetriono (2006) menyatakan bahwa metode dokumentasi merupakan studi kepustakaan untuk mendapatkan data sekunder. Data tersebut berupa data-data yang telah tersedia dan diperoleh dari instansi dan pihakpihak terkait yang berhubungan dengan penelitian. Data-data tersebut diperoleh dari poster dan brosur agroindustri kopi cap Lereng Tancak Kembar di Kecamatan Pakem Kabupaten Bondowoso, serta literatur lain yang mencakup dan mendukung dalam penelitian. Marjin pemasaran merupakan perbedaan harga ditingkat produsen dengan harga ditingkat pengecer atau harga yang harus dibayarkan konsumen akhir. Marjin pemasaran pada pemasaran kopi cap Lereng Tancak Kembar di 
Dinda Dara A., Titin A., Sri Subekti: Saluran dan Margin Pemasaran Kopi...

Kecamatan Pakem menggunakan analisis marjin pemasaran. Secara sistematis marjin pemasaran dapat dirumuskan sebagai berikut:

Keterangan:

$$
\mathrm{MP}=\mathrm{Pr}-\mathrm{Pf}
$$

$\mathrm{MP}=$ Marjin pemasaran kopi $(\mathrm{Rp} / \mathrm{kg})$

$\operatorname{Pr}=$ Harga kopi di tingkat retail/ konsumen akhir (Rp/kg)

Pf = Harga kopi di tingkat agroindustri $(\mathrm{Rp} / \mathrm{kg})$

Kriteria pengambilan keputusan:

Semakin kecil margin pemasaran, maka semakin efisien pemasaran kopi cap Lereng Tancak Kembar di Kecamatan Pakem Kabupaten Bondowoso.

Menurut Suherman, et.al (2011), share biaya dan keuntungan pada masing-masing lembaga pemasaran dirumuskan sebagai berikut:

Sbi $=($ bi $/$ Pr $) \times 100 \%$

$\mathrm{Ski}=(\mathrm{ki} / \mathrm{Pr}) \times 100 \%$

Keterangan:

Sbi = share biaya pemasaran ke-i.

Ski = share keuntungan lembaga pemasaran ke-i.

Menurut Dyanasari, et.al (2010), distribusi marjin pemasaran dirumuskan:

$$
\begin{gathered}
\text { Sbi }=(\mathrm{Bi}) /(\operatorname{Pr}-\mathrm{Pf}) \times 100 \% \\
B i=\sum_{i=1}^{n=k} b i j \\
\text { Ski }=(\mathrm{Ki}) /(\operatorname{Pr}-\mathrm{Pf}) \times 100 \% \\
K i=\operatorname{Pji} \mathrm{Pbi}-\sum_{i=1}^{n=k} b i j
\end{gathered}
$$

Keterangan:

Sbi $=\underset{\text { Share }}{\text { pemasaran ke- } \mathrm{i}}$ pemasaran lembaga

$\mathrm{Bi}=$ Biaya pemasaran lembaga ke-i $(\mathrm{Rp} / \mathrm{kg})$

$\mathrm{Bij}=$ Biaya pemasaran lembaga ke-i dari berbagai jenis biaya mulai $\mathrm{j}=1$ sampai ke-n

$\operatorname{Pr}=$ Harga di tingkat pengecer atau konsumen akhir $(\mathrm{Rp} / \mathrm{kg}$

Pf $=$ Harga di tingkat produsen $(\mathrm{Rp} / \mathrm{kg})$

Ski = Share keuntungan pemasaran lembaga pemasaran ke-i

$$
\begin{aligned}
\mathrm{Ki}= & \begin{array}{l}
\text { Keuntungan pemasaran lembaga } \\
\text { pemasaran ke } \mathrm{i}
\end{array} \\
\mathrm{Pji}= & \begin{array}{l}
\text { Harga jual lembaga pemasaran ke-i } \\
(\mathrm{Rp} / \mathrm{kg})
\end{array} \\
\mathrm{Pbi}= & \begin{array}{l}
\text { Harga beli lembaga pemasaran ke- } \\
(\mathrm{Rp} / \mathrm{kg})
\end{array}
\end{aligned}
$$

\section{HASIL DAN PEMBAHASAN}

\section{Saluran Pemasaran Kopi Cap Lereng \\ Tancak Kembar di Desa Andungsari Kecamatan Pakem Kabupaten Bondowoso}

Pemasaran adalah kegiatan penyampaian barang dari produsen hingga ke konsumen. Hasil penelitian terkait dengan pemasaran kopi cap lereng tancak kembar di Desa Andungsari Kecamatan Pakem Kabupaten Bondowoso menunjukkan bahwa terdapat beberapa saluran pemasaran kopi yang ada di daerah tersebut, maka peneliti membagi saluran pemasaran berdasarkan jenis produk kopi. Berdasarkan jenis produk kopi yang digunakan dalam proses produksi di agroindustri Lereng Tancak Kembar, saluran pemasaran kopi cap Lereng Tancak Kembar dibagi menjadi dua macam, yaitu pemasaran kopi cap Lereng Tancak Kembar jenis arabika dan pemasaran kopi cap Lereng Tancak Kembar jenis robusta.

Proses pemasaran kopi pada agroindustri cap Lereng Tancak Kembar semakin lama terus mengalami kemajuan. Hal tersebut dapat dilihat dari 2 hal, pertama adalah pada saat awal berdirinya agroindustri Lereng Tancak Kembar sangat mengalami kesulitan untuk memasarkan produknya dikarenakan akses jalan yang sulit dan tidak ada tujuan pasar yang jelas. Namun sekarang proses pemasaran kopi cap Lereng Tancak Kembar telah memiliki tujuan pasar yang jelas. Kedua, beberapa tahun yang lalu agroindustri harus mengirim produknya sendiri kepada pedagang yang ada di kota, namun sekarang berbanding terbalik, dimana lembaga yang ingin membeli kopi langsung datang ke tempat agroindustri untuk mendapatkan kopi yang diinginkan. Pemasaran kopi Cap Lereng Tancak Kembar jenis arabika adalah pemasaran kopi dimana kopi yang dipasarkan hanyalah kopi arabika. Kopi yang dipasarkan adalah kopi yang sudah berbentuk bubuk yang dihasilkan dari kopi gelondong melalui metode olah basah. Pemasaran kopi jenis arabika ini terdiri dari dua saluran yang selanjutnya akan disebut dengan saluran 1 dan saluran 2 . 
Dinda Dara A., Titin A., Sri Subekti: Saluran dan Margin Pemasaran Kopi...

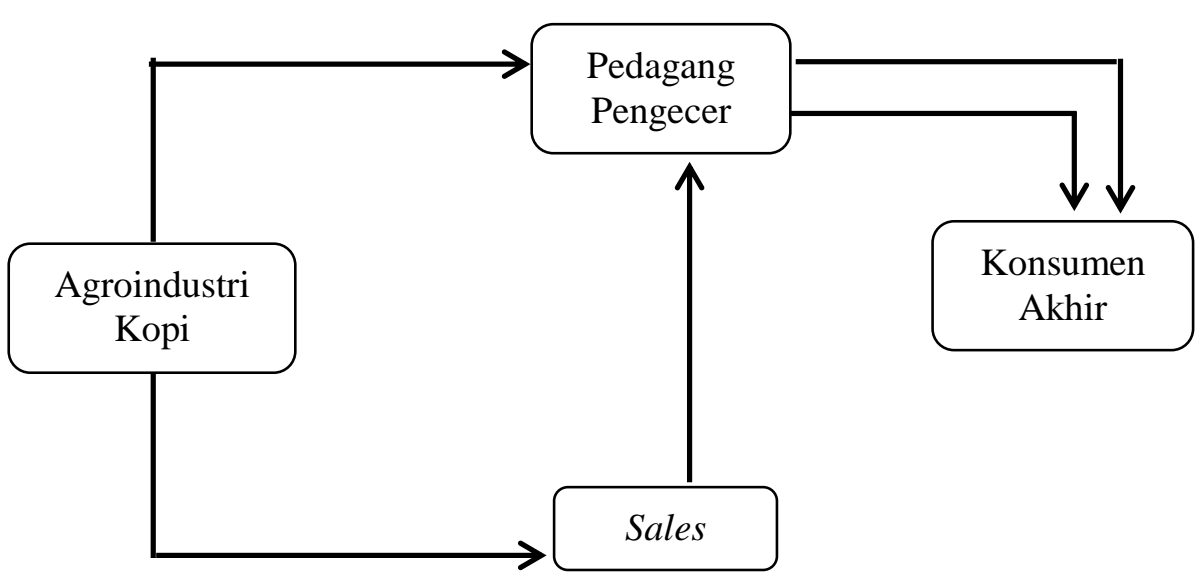

Gambar 1. Saluran Pemasaran Kopi Arabika Cap Lereng Tancak Kembar

Keterangan :

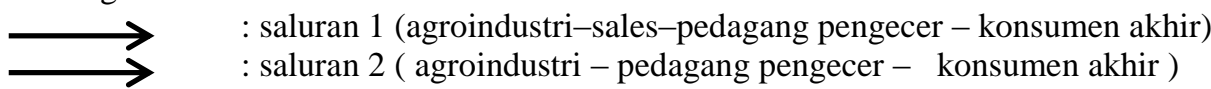

Berdasarkan Gambar 1 diatas dapat diketahui bahwa Saluran pemasaran 1 terdiri dari agroindustri - sales - pedagang pengecer konsumen akhir, dan Saluran pemasaran 2 terdiri dari agroindustri - pedagang pengecer konsumen akhir. Agroindustri kopi pada pemasaran kopi cap Lereng Tancak Kembar ini adalah agroindustri yang melakukan pengolahan kopi gelondong menjadi bubuk kopi. Agroindustri yang dimaksud adalah agroindustri Lereng Tancak Kembar. Agroindustri mendapatkan pasokan bahan baku kopi gelondong dari petani kopi arabika yang ada di Desa Andungsari dan sekitarnya.

Proses pengolahan kopi gelondong arabika menjadi kopi bubuk memiliki beberapa tahapan berdasarkan Standar Operasinal Prosedure (SOP) yang dimiliki oleh agroindustri Lereng Tancak Kembar. Tahapantahapan tersebut antara lain : (1) sortasi buah kopi, (2) perambangan buah kopi (memisahkan buah kopi yang terapung), (3) pengupasan kulit buah kopi (pengupasan menggunakan mesin pupler), (4) pembersihkan dan pencucian biji kopi berkulit tanduk basah (memisahkan dari kulit kopi, biji kopi hampa dan kotoran lain), (5) fermentasi selama 18-36 jam, (6) pencucian dengan air bersih, (7) penirisan dan penjemuran (pengadukan dan pembalikan setiap jam sampai kadar air 12\%), (8) penyimpanan biji kulit tanduk kering (sementara), (9) penggerbusan, dan (10) kopi bubuk cap Lereng Tancak Kembar siap kirim atau jual. Dalam satu kali proses produksi agroindustri membutuhkan waktu sebelas hari.

Kopi yang telah dilakukan proses perambangan kemudian dikupas dengan menggunakan mesin pulper. Setelah selesai dilakukan pengupasan kemudian kopi dicuci dan dibersihkan dari kulit kopi dan kotorankotoran lain. Kopi yang telah bersih dan tidak tercampur dengan kotoran lain kemudian difermentasi selama 18 jam karena kopi bubuk arabika diolah menggunakan metode olah basah yang kadar airnya harus dijaga. Setelah dilakukan proses fermentasi kemudian kopi arabika tersebut dicuci dengan menggunakan ari bersih serta dijemur sampai kadar air kopi menjadi $12 \%$. Setelah dijemur biji kopi kemudian disimpan untuk sementara untuk kemdian bisa dilakukan penggerbusan. Setelah proses penggerbusan selesai kemudian bubuk kopi dikemas dan siap untuk dijual atau dipasarkan.

Sales kopi pada pemasaran kopi cap Lereng Tancak Kembar adalah pedagang yang membeli produk kopi di agroindustri kopi kemudian menjualnya kembali kepada pedagang pengecer kopi. Sales pada saluran 1 mendapatkan kopi dari agroindustri dengan cara datang langsung ke tempat agroindustri. Berbeda dengan saluran 2, dimana pada saluran tersebut agroindustri langsung menjual kopi kepada pedagang pengecer tanpa melalui sales. Transportasi yang digunakan oleh sales pada saluran 1 adalah sepada motor. Rata-rata 
pengambilan kopi bubuk cap Lereng Tancak Kembar oleh sales adalah sebesar 31 kilogram, yang terdiri dari 19 kilogram kopi bubuk jenis arabika dan 12 kilogram kopi bubuk jenis robusta. Sistem pembayaran yang dilakukan antara sales dan agroindustri kopi adalah sistem cash. Pembayaran dilakukan sesaat setelah sales mendapatkan produk yang diinginkan. Sales yang terdapat di agroindustri Lereng Tancak Kembar adalah sales yang telah bekerjasama dengan agroindustri dalam kurun waktu yang cukup lama. Melalui sales pihak agroindustri telah mengetahui tentang jumlah produk yang dibutuhkan oleh konsumen dalam periode waktu tertentu.

Pedagang pengecer kopi pada pemasaran kopi cap Lereng Tancak Kembar adalah lembaga yang membeli kopi bubuk dan menjualnya kembali kepada konsumen akhir. Pedagang pengecer pada pemasaran ini terbagi menjadi dua macam, yaitu pedagang pengecer pada saluran 1 dan pedagang pengecer pada saluran 2. Kedua pedagang pengecer tersebut dibedakan berdasarkan cara mendapatkan produk kopi dari lembaga sebelumnya atau lembaga yang menjual kopi bubuk. Pedagang pengecer kopi pada saluran 1 dalam mendapatkan produk tidak perlu mengeluarkan tambahan biaya selain harga kopi yang harus dibayarkan. Hal tersebut dikarenakan biaya transportasi sepenuhnya ditanggung oleh sales kopi. Berbeda dengan pedagang pengecer kopi pada saluran 2, dimana pedagang pengecer pada saluran tersebut untuk dapatkan produk harus mengeluarkan biaya tambahan berupa biaya transportasi. Hal tersebut dikarenakan pada saluran 2 tidak terdapat lembaga sales sebagai lembaga perantara. Sehingga pedagang pengecer harus datang langsung ke tempat agroindustri.

Berdasarkan penjelasan diatas dapat disimpulkan bahwa saluran pemasaran 2 memiliki saluran yang lebih pendek jika dibandingkan dengan saluran 1 . Pebedaan pada kedua saluran tersebut adalah lembaga pembeli setelah agroindustri. Agroindustri pada saluran 1 menjual kopi kepada sales untuk kemudian disalurkan kepada pedagang pengecer hingga sampai pada konsumen akhir. Sedangkan agroindustri pada saluran 2 langsung menjual kopi kepada pedagang pengecer tanpa melalui sales. Hal tersebut membuat margin pemasaran pada kedua saluran tersebut berbeda. Selanjutnya adalah saluran pemasaran kopi jenis robusta.

Pemasaran kopi Cap Lereng Tancak Kembar jenis robusta adalah pemasaran kopi dimana kopi yang dipasarkan hanyalah kopi robusta. Kopi yang dipasarkan tersebut adalah kopi yang sudah berbentuk bubuk yang dihasilkan dari kopi olah kering. Pemasaran kopi jenis robusta terdiri dari dua saluran yang selanjutnya akan disebut dengan saluran 1 dan saluran 2.

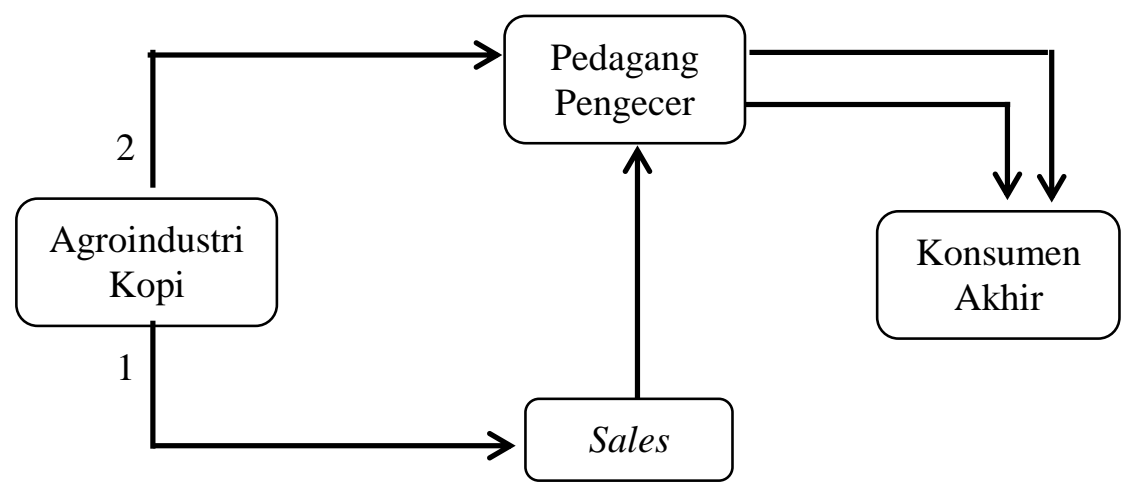

Gambar 2. Saluran Pemasaran Kopi Robusta Cap Lereng Tancak Kembar

Keterangan :

$\longrightarrow \quad$ : saluran 1 ( agroindustri - sales - pedagang pengecer - konsumen akhir )

: saluran 2 ( agroindustri - pedagang pengecer - konsumen akhir) 
Dinda Dara A., Titin A., Sri Subekti: Saluran dan Margin Pemasaran Kopi...

Berdasarkan Gambar 2 diatas dapat diketahui bahwa Saluran pemasaran 1 terdiri dari: agroindustri - sales - pedagang pengecer - konsumen akhir, dan saluran 2 terdiri agroindustri - pedagang pengecer - konsumen akhir. Kopi gelondong jenis robusta yang telah dibeli dari petani kemudian langsung dilakukan proses sortasi oleh agroindustri. Sortasi dilakukan untuk memisahkan kopi yang telah matang sempurna dengan kopi yang belum matang sempurna. Indikator kematangan kopi dapat dilihat dari warna kulit kopi itu sendiri, warna merah pada kulit kopi menunjukkan bahwa kopi tersebut telah matang sempurna. Kopi yang telah disortir kemudian dilakukan dilakukan proses perambangan dengan menggunakan air. Perambangan bertujuan untuk memisahkan kopi yang berisi dengan kopi yang tidak berisi. Kopi yang berisi biasanya tenggelam atau ada yang melayang di air, sedangkan kopi yang tidak berisi mengapung ketika dilakukan perambangan.

Kopi yang telah dilakukan proses perambangan kemudian dikupas dengan menggunakan mesin pupler. Setelah selesai dilakukan pengupasan kemudian kopi dicuci dan dibersihkan dari kulit kopi dan kotorankotoran lain. Kopi yang telah bersih dan tidak tercampur dengan kotoran lain kemudian difermentasi. Perbedaannya antara fermentasi kopi arabika dan fermentasi kopi robusta adalah terletak pada waktu fermentasi. Fermentasi pada kopi robusta dilakukan selama 36 jam, sedangkan fermentasi kopi arabika hanya memerlukan waktu selama 18 jam. Hal tersebut karena kopi bubuk robusta diolah menggunakan metode olah kering yang kadar airnya harus benar-benar sedikit. Setelah dilakukan proses fermentasi kemudian kopi robusta tersebut dicuci dengan menggunakan air bersih serta dijemur sampai kadar air kopi menjadi 22\%. Setelah dijemur biji kopi kemudian disimpan untuk sementara untuk kemudian bisa dilakukan penggerbusan. Setelah proses penggerbusan selesai kemudian bubuk kopi dikemas dan siap untuk dijual atau dipasarkan.

Lembaga yang menjadi tujuan penjualan agroindustri pada saluran 1 adalah sales. Sales mendapatkan kopi dari agroindustri dengan cara datang langsung ke tempat agroindustri. Berbeda dengan saluran 2 dimana tidak terdapat lembaga sales sebagai penyusun saluran pemasarannya. Transportasi yang digunakan oleh sales adalah sepada motor. Rata-rata pengambilan kopi bubuk cap Lereng Tancak Kembar oleh sales adalah sebesar 31 kilogram, yang terdiri dari 19 kilogram kopi bubuk jenis arabika dan 12 kilogram kopi bubuk jenis robusta. Sistem pembayaran yang dilakukan antara sales dan agroindustri kopi adalah sistem cash. Pembayaran dilakukan sesaat setelah sales mendapatkan produk yang diinginkan. Sales yang terdapat di agroindustri Lereng Tancak Kembar adalah sales yang telah bekerjasama dengan agroindustri dalam kurun waktu yang cukup lama. Melalui sales pihak agroindustri telah mengetahui tentang jumlah produk yang dibutuhkan oleh konsumen dalam periode waktu tertentu.

Pedagang pengecer kopi pada pemasaran kopi cap Lereng Tancak Kembar adalah lembaga yang membeli kopi bubuk dan menjualnya kembali kepada konsumen akhir. Pedagang pengecer pada pemasaran ini terbagi menjadi dua macam seperti pada saluran pemasaran kopi arabika, yaitu pedagang pengecer pada saluran 1 dan pedagang pengecer pada saluran 2. Kedua pedagang pengecer tersebut dibedakan berdasarkan cara mendapatkan produk kopi dari lembaga sebelumnya atau lembaga yang menjual kopi bubuk. Pedagang pengecer kopi pada saluran 1 dalam mendapatkan produk tidak perlu mengeluarkan tambahan biaya selain harga kopi yang harus dibayarkan. Hal tersebut dikarenakan biaya transportasi sepenuhnya ditanggung oleh sales kopi. Berbeda dengan pedagang pengecer kopi pada saluran 2, dimana pedagang pengecer pada saluran tersebut untuk dapatkan produk harus mengeluarkan biaya tambahan berupa biaya transportasi. Hal tersebut dikarenakan pada saluran 2 tidak terdapat lembaga sales sebagai lembaga perantara. Sehingga pedagang pengecer harus datang langsung ke tempat agroindustri.

Berdasarkan penjelasan diatas dapat disimpulkan bahwa saluran pemasaran 2 kopi robusta memiliki saluran yang lebih pendek jika dibandingkan dengan saluran 1. Pebedaan pada kedua saluran tersebut adalah terletak pada lembaga pembeli setelah agroindustri. Jika agroindustri pada saluran 1 menjual kopi kepada sales untuk kemudian disalurkan kepada pedagang pengecer hingga sampai pada konsumen akhir. Maka lain halnya dengan 
Dinda Dara A., Titin A., Sri Subekti: Saluran dan Margin Pemasaran Kopi...

saluran 2, agroindustri pada tersebut langsung menjual kopi kepada pedagang pengecer tanpa melalui sales. Hal tersebut membuat margin pemasaran pada kedua saluran tersebut berbeda.

Marjin Pemasaran pada Pemasaran Kopi Cap Lereng Tancak Kembar di Desa Andungsari Kecamatan Pakem Kabupaten Bondowoso

Ali et al. (2015) menyatakan marjin pemasaran adalah selisih harga yang dibayar konsumen dan harga yang diterima produsen. Indikator yang membentuk marjin pemasaran adalah biaya-biaya yang diperlukan untuk melaksanakan fungsi-fungsi pemasaran serta keuntungan lembaga pemasaran. Keuntungan dari setiap lembaga pemasaran terlibat dalam aktivitas pemasaran komoditi. Marjin pemasaran kopi Cap Lereng Tancak Kembar dibagi menjadi 2 macam, yaitu marjin pemasaran pada kopi cap Lereng Tancak Kembar jenis arabika dan jenis robusta. Berikut ini adalah marjin pemasaran kopi cap Lereng Tancak Kembar.

Tabel 1 menunjukkan bahwa saluran pemasaran 1 meliputi agroindustri kopi - sales kopi bubuk - pedagang pengecer kopi konsumen akhir kopi. Saluran 1 ini menunjukkan bahwa harga kopi arabika di tingkat agroindustri sebesar Rp. 166.670,00 per kilogram. Harga kopi arabika cap Lereng Tancak Kembar di tingkat konsumen akhir sebesar Rp. 253.330,00 per kilogram. Berdasarkan hal tersebut, maka dapat diketahui marjin pemasaran dari pemasaran kopi cap Lereng Tancak Kembar pada saluran 1 adalah sebesar Rp. 86.660,00 per kilogram.

Agroindustri kopi pada saluran 1 tidak mengeluarkan biaya pemasaran dikarenakan sales kopi langsung datang ke tempat agroindustri untuk membeli kopi bubuk cap Lereng Tancak Kembar. Biaya pemasaran yakni berupa biaya transportasi sebesar Rp. $3.157,89$ per kilogram atau 1,25\% ditanggung sepenuhnya oleh sales kopi bubuk cap Lereng Tancak Kembar. Harga jual kopi bubuk dari sales ke pedagang pengecer sebesar $\mathrm{Rp}$. 206.670,00 per kilogram, sehingga sales memperoleh keuntungan sebesar Rp. $36.842,11 / \mathrm{kg}$ atau $14,54 \%$. Harga jual kopi cap Lereng Tancak Kembar dari pedagang

Tabel 1. Marjin Pemasaran pada Pemasaran Kopi Arabika Cap Lereng Tancak Kembar pada Saluran 1

\begin{tabular}{|c|c|c|c|c|c|c|}
\hline \multirow{2}{*}{ No. } & \multirow{2}{*}{ Lembaga Pemasaran } & \multirow{2}{*}{$\begin{array}{c}\text { Harga } \\
(\mathrm{Rp} / \mathrm{Kg})\end{array}$} & \multicolumn{2}{|c|}{ Share (\%) } & \multicolumn{2}{|c|}{$\mathrm{DM}(\%)$} \\
\hline & & & Ski & Sbi & Ski & Sbi \\
\hline \multirow[t]{2}{*}{1.} & Agroindustri & & & & & \\
\hline & a. Harga Jual & $166.670,00$ & 65,79 & & & \\
\hline \multirow[t]{5}{*}{2.} & Sales Kopi bubuk & & & & & \\
\hline & a. Harga Beli & $166.670,00$ & & & & \\
\hline & b. Biaya Transportasi & $3.157,89$ & & 1,25 & & 3,64 \\
\hline & c. Harga Jual & $206.670,00$ & & & & \\
\hline & d. Keuntungan & $36.842,11$ & 14,54 & & 42,51 & \\
\hline \multirow[t]{4}{*}{3.} & Pedagang Pengecer & & & & & \\
\hline & a. Harga Beli & $206.670,00$ & & & & \\
\hline & b. Harga Jual & $253.330,00$ & & & & \\
\hline & c. Keuntungan & $46.660,00$ & 18,42 & & 53,84 & \\
\hline \multirow[t]{2}{*}{4.} & Konsumen Akhir Kopi & & & & & \\
\hline & a. Harga Beli & $253.330,00$ & & & & \\
\hline \multicolumn{2}{|r|}{ Margin Pemasaran (MP) } & $86.660,00$ & 98,75 & 1,25 & 96,36 & 3,64 \\
\hline \multicolumn{2}{|r|}{ Total } & & \multicolumn{2}{|c|}{100} & \multicolumn{2}{|c|}{100} \\
\hline
\end{tabular}

Sumber: Data Primer Diolah Tahun 2018 
pengecer ke konsumen akhir pada saluran 1 adalah sebesar Rp. 253.330,00 per kilogram, sehingga keuntungan yang diperoleh pedagang pengecer kopi sebesar Rp. 46.660,00 per kilogram atau $18,42 \%$.

Besar nilai share keuntungan secara keseluruhan pada pemasaran kopi cap Lereng Tancak Kembar saluran 1 sebesar 98,75\% dengan share biaya sebesar $1,25 \%$. Berdasarkan hal tersebut dapat disimpulkan bahwa pemasaran kopi saluran 1 tergolong menguntungkan karena nilai share keuntungan lebih besar dari nilai share biaya. Analisis Distribusi Marjin pada pemasaran kopi cap Lereng Tancak Kembar menunjukkan sebaran keuntungan yang diperoleh masing-masing lembaga penyusun pemasaran kopi di daerah tersebut. Lembaga yang mendapatkan bagian keuntungan terbesar adalah pedagang pengecer, yaitu sebesar 53,84\%, dan lembaga yang mendapatkan bagian keuntungan terkecil adalah sales kopi, yaitu sebesar 14,96\%. Sedangkan sales kopi cap Lereng Tancak Kembar mendapatkan bagian keuntungan masing sebesar $42,51 \%$. Berikutnya adalah marjin pemasaran kopi arabika cap Lereng Tancak Kembar saluran 2.

Tabel 2 menunjukkan bahwa saluran pemasaran 2 meliputi agroindustri kopi pedagang pengecer - konsumen akhir kopi. Pada saluran ini menunjukkan bahwa harga kopi di tingkat agroindustri sebesar $\mathrm{Rp}$.
180.000,00 per kilogram. Sedangkan harga kopi cap Lereng Tancak Kembar di tingkat konsumen akhir sebesar Rp. 233.330,00 per kilogram. Harga tersebut lebih rendah dari pada harga di tingkat konsumen pada saluran 1 . Berdasarkan hal tersebut, maka dapat diketahui marjin pemasaran dari pemasaran kopi cap Lereng Tancak Kembar pada saluran 2 adalah sebesar Rp. 53.330,00 per kilogram.

Walaupun tanpa menggunakan sales, namun agroindustri kopi pada saluran 2 juga tidak mengeluarkan biaya pemasaran dikarenakan pedagang pengecer pada saluran tersebut berbeda dengan pedagang pengecer pada saluran 1. Pedagang pengecer kopi pada saluran 2 langsung datang ke tempat agroindustri untuk membeli kopi bubuk cap Lereng Tancak Kembar. Biaya pemasaran yakni berupa biaya transportasi sebesar $\mathrm{Rp}$. $3.333,33$ per kilogram atau 1,43\% ditanggung sepenuhnya oleh pedagang pengecer kopi. Harga jual kopi cap Lereng Tancak Kembar dari pedagang pengecer ke konsumen akhir pada saluran 2 adalah sebesar Rp. 233.330,00 per kilogram, sehingga keuntungan yang diperoleh pedagang pengecer kopi sebesar Rp. 49.996,67 per kilogram atau 21,43\%.

Besar nilai share keuntungan secara keseluruhan pada pemasaran kopi cap Lereng Tancak Kembar saluran 2 sebesar 98,57\% dengan share biaya sebesar 1,43\%.

Tabel 2. Marjin Pemasaran pada Pemasaran Kopi Arabika Cap Lereng Tancak Kembar pada Saluran 2

\begin{tabular}{|c|c|c|c|c|c|c|}
\hline \multirow{2}{*}{ No. } & \multirow{2}{*}{ Lembaga Pemasaran } & \multirow{2}{*}{$\frac{\text { Harga }}{(\mathrm{Rp} / \mathrm{Kg})}$} & \multicolumn{2}{|c|}{ Share $(\%)$} & \multicolumn{2}{|c|}{$\mathrm{DM}(\%)$} \\
\hline & & & Ski & Sbi & Ski & Sbi \\
\hline \multirow[t]{2}{*}{1.} & Agroindustri & & & & & \\
\hline & a. Harga Jual & $180.000,00$ & 77,14 & & & \\
\hline \multirow[t]{5}{*}{2.} & Pedagang Pengecer & & & & & \\
\hline & a. Harga Beli & $180.000,00$ & & & & \\
\hline & b. Biaya Transportasi & 333,33 & & 1,43 & & 6,25 \\
\hline & c. Harga Jual & $233.330,00$ & & & & \\
\hline & d. Keuntungan & $49.996,67$ & 21,43 & & 93,75 & \\
\hline \multirow[t]{2}{*}{3.} & Konsumen Akhir Kopi & & & & & \\
\hline & a. Harga Beli & $233.330,00$ & & & & \\
\hline & Margin Pemasaran (MP) & $53.330,00$ & 98,57 & 1,43 & 93,75 & 6,25 \\
\hline & Total & & & & 10 & \\
\hline
\end{tabular}

Sumber : Data Primer Diolah Tahun 2018 
Dinda Dara A., Titin A., Sri Subekti: Saluran dan Margin Pemasaran Kopi...

Berdasarkan hal tersebut dapat disimpulkan bahwa pemasaran kopi saluran 2 tergolong menguntungkan karena nilai share keuntungan lebih besar dari nilai share biaya. Analisis Distribusi Marjin pada pemasaran kopi cap Lereng Tancak Kembar menunjukkan sebaran keuntungan yang diperoleh masingmasing lembaga penyusun pemasaran kopi cap Lereng Tancak Kembar. Lembaga yang mendapatkan bagian keuntungan terbesar adalah pedagang pengecer, yaitu sebesar $93,75 \%$.

Berdasarkan penjelasan diatas dapat disimpulkan bahwa margin pemasaran pada saluran 2 sebesar Rp. 53.330,-/kg lebih kecil dari pada marjin pemasaran pada saluran 1, yaitu sebesar Rp. 86.660,- /kg. Besar marjin pemasaran dapat dijadikan salah satu tolak ukur untuk menentukan eifisien pemasaran. Berdasarkan nilai marjin pemasaran diatas, dapat disimpulkan bahwa saluran pemasaran 2 lebih eifisien dibandingkan dengan saluran 1 . Besar marjin pada kedua saluran tersebut dipengaruhi oleh harga produk di tingkat konsumen akhir dan harga di tingkat produsen.

Tabel 3 menunjukkan bahwa saluran pemasaran 1 meliputi agroindustri kopi - sales kopi bubuk - pedagang pengecer kopi konsumen akhir kopi. Saluran 1 ini menunjukkan bahwa harga kopi robusta di tingkat agroindustri sebesar Rp. 70.000,00 per kilogram. Harga kopi robusta cap Lereng Tancak Kembar di tingkat konsumen akhir sebesar Rp. 170.000,00 per kilogram. Berdasarkan hal tersebut, maka dapat diketahui marjin pemasaran dari pemasaran kopi cap Lereng Tancak Kembar pada saluran 1 adalah sebesar Rp. 100.000,00 per kilogram.

Agroindustri kopi pada saluran 1 tidak mengeluarkan biaya pemasaran dikarenakan sales kopi langsung datang ke tempat agroindustri untuk membeli kopi bubuk cap Lereng Tancak Kembar. Biaya pemasaran yakni berupa biaya transportasi sebesar Rp. $3.157,89$ per kilogram atau 1,86\% ditanggung sepenuhnya oleh sales kopi bubuk cap Lereng Tancak Kembar. Harga jual kopi bubuk dari sales ke pedagang pengecer sebesar $\mathrm{Rp}$. $110.000,00$ per kilogram, sehingga sales memperoleh keuntungan sebesar Rp. $36.842,11 / \mathrm{kg}$ atau $21,67 \%$. Harga jual kopi cap Lereng Tancak Kembar dari pedagang pengecer ke konsumen akhir pada saluran 1

Tabel 3. Marjin Pemasaran pada Pemasaran Kopi Robusta Cap Lereng Tancak Kembar pada Saluran 1

\begin{tabular}{|c|c|c|c|c|c|c|}
\hline \multirow{2}{*}{ No. } & \multirow{2}{*}{ Lembaga Pemasaran } & \multirow{2}{*}{$\begin{array}{c}\text { Harga } \\
(\mathrm{Rp} / \mathrm{Kg})\end{array}$} & \multicolumn{2}{|c|}{ Share (\%) } & \multicolumn{2}{|c|}{$\mathrm{DM}(\%)$} \\
\hline & & & Ski & Sbi & Ski & Sbi \\
\hline \multirow[t]{2}{*}{1.} & Agroindustri & & & & & \\
\hline & a. Harga Jual & $70.000,00$ & 41,18 & & & \\
\hline \multirow[t]{5}{*}{2.} & Sales Kopi bubuk & & & & & \\
\hline & a. Harga Beli & $70.000,00$ & & & & \\
\hline & b. Biaya Transportasi & $3.157,89$ & & 1,86 & & 3,16 \\
\hline & c. Harga Jual & $110.000,00$ & & & & \\
\hline & d. Keuntungan & $36.842,11$ & 21,67 & & 36,84 & \\
\hline \multirow[t]{4}{*}{3.} & Pedagang Pengecer & & & & & \\
\hline & a. Harga Beli & $110.000,00$ & & & & \\
\hline & b. Harga Jual & $170.000,00$ & & & & \\
\hline & c. Keuntungan & $60.000,00$ & 35,29 & & 60,00 & \\
\hline \multirow[t]{4}{*}{4.} & Konsumen Akhir Kopi & & & & & \\
\hline & a. Harga Beli & $170.000,00$ & & & & \\
\hline & Margin Pemasaran (MP) & $100.000,00$ & 98,14 & 1,86 & 96,84 & 3,16 \\
\hline & Total & & & & & \\
\hline
\end{tabular}

Sumber : Data Primer Diolah Tahun 2018 
adalah sebesar Rp. 170.000,00 per kilogram, sehingga keuntungan yang diperoleh pedagang pengecer kopi sebesar Rp. 60.000,00 per kilogram atau $35,29 \%$.

Besar nilai share keuntungan secara keseluruhan pada pemasaran kopi cap Lereng Tancak Kembar saluran 1 sebesar 98,14\% dengan share biaya sebesar $1,86 \%$. Berdasarkan hal tersebut dapat disimpulkan bahwa pemasaran kopi saluran 1 tergolong menguntungkan karena nilai share keuntungan lebih besar dari nilai share biaya. Analisis Distribusi Marjin pada pemasaran kopi cap Lereng Tancak Kembar menunjukkan sebaran keuntungan yang diperoleh masing-masing lembaga penyusun pemasaran kopi di daerah tersebut. Lembaga yang mendapatkan bagian keuntungan terbesar adalah pedagang pengecer, yaitu sebesar $60,00 \%$, dan lembaga yang mendapatkan bagian keuntungan terkecil adalah sales kopi, yaitu sebesar $36,84 \%$.

Tabel 4 menunjukkan bahwa saluran pemasaran 2 meliputi agroindustri kopi pedagang pengecer - konsumen akhir kopi. pada saluran ini menunjukkan bahwa harga kopi di tingkat agroindustri sebesar Rp. $80.000,00$ per kilogram. Sedangkan harga kopi cap Lereng Tancak Kembar di tingkat konsumen akhir sebesar Rp. 165.000,00 per kilogram. Harga tersebut lebih rendah dari pada harga di tingkat konsumen pada saluran 1 . Berdasarkan hal tersebut, maka dapat diketahui marjin pemasaran dari pemasaran kopi cap
Lereng Tancak Kembar pada saluran 2 adalah sebesar Rp. 85.000,00 per kilogram.

Walaupun tanpa menggunakan sales, namun agroindustri kopi pada saluran 2 juga tidak mengeluarkan biaya pemasaran dikarenakan pedagang pengecer pada saluran tersebut berbeda dengan pedagang pengecer pada saluran 1. Pedagang pengecer kopi pada saluran 2 langsung datang ke tempat agroindustri untuk membeli kopi bubuk cap Lereng Tancak Kembar. Biaya pemasaran yakni berupa biaya transportasi sebesar $\mathrm{Rp}$. $3.333,33$ per kilogram atau 2,02\% ditanggung sepenuhnya oleh pedagang pengecer kopi. Harga jual kopi cap Lereng Tancak Kembar dari pedagang pengecer ke konsumen akhir pada saluran 2 adalah sebesar Rp. 165.000,00 per kilogram, sehingga keuntungan yang diperoleh pedagang pengecer kopi sebesar Rp. $81.666,67$ per kilogram atau 49,49\%.

Besar nilai share keuntungan secara keseluruhan pada pemasaran kopi cap Lereng Tancak Kembar saluran 2 sebesar 97,98\% dengan share biaya sebesar 2,02\%. Berdasarkan hal tersebut dapat disimpulkan bahwa pemasaran kopi saluran 2 menguntungkan karena nilai share keuntungan lebih besar dari nilai share biaya. Analisis Distribusi Marjin pada pemasaran kopi cap Lereng Tancak Kembar menunjukkan sebaran Keuntungan yang diperoleh masing-masing lembaga penyusun pemasaran kopi cap Lereng Tancak Kembar.

Tabel 4. Marjin Pemasaran pada Pemasaran Kopi Robusta Cap Lereng Tancak Kembar pada Saluran 2

\begin{tabular}{|c|c|c|c|c|c|c|}
\hline \multirow{2}{*}{ No. } & \multirow{2}{*}{ Lembaga Pemasaran } & \multirow{2}{*}{$\frac{\text { Harga }}{(\mathrm{Rp} / \mathrm{Kg})}$} & \multicolumn{2}{|c|}{ Share (\%) } & \multicolumn{2}{|c|}{$\mathrm{DM}(\%)$} \\
\hline & & & Ski & Sbi & Ski & Sbi \\
\hline \multirow[t]{2}{*}{1.} & Agroindustri & & & & & \\
\hline & a. Harga Jual & $80.000,00$ & 48,48 & & & \\
\hline \multirow[t]{5}{*}{2.} & Pedagang Pengecer & & & & & \\
\hline & a. Harga Beli & $80.000,00$ & & & & \\
\hline & b. Biaya Transportasi & 333,33 & & 2,02 & & 3,92 \\
\hline & c. Harga Jual & $165.000,00$ & & & & \\
\hline & d. Keuntungan & 81.666 .67 & 49,49 & & 96,08 & \\
\hline \multirow[t]{2}{*}{3.} & Konsumen Akhir Kopi & & & & & \\
\hline & a. Harga Beli & $165.000,00$ & & & & \\
\hline & Margin Pemasaran (MP) & $85.000,00$ & 97,98 & 2,02 & 96,08 & 3,92 \\
\hline & Total & & 10 & & & \\
\hline
\end{tabular}

Sumber : Data Primer Diolah Tahun 2018 
Dinda Dara A., Titin A., Sri Subekti: Saluran dan Margin Pemasaran Kopi...

Lembaga yang mendapat keuntungan terbesar adalah pedagang pengecer, sebesar $96,08 \%$.

Berdasarkan penjelasan diatas dapat disimpulkan bahwa margin pemasaran pada saluran 2 sebesar Rp. 85.000,-/kg lebih kecil dari pada marjin pemasaran pada saluran 1, yaitu sebesar Rp. 100.000,- /kg. Berdasarkan nilai marjin pemasaran diatas, dapat disimpulkan bahwa saluran pemasaran 2 lebih eifisien dibandingkan dengan saluran 1. Besar marjin pada kedua saluran tersebut dipengaruhi oleh harga produk di tingkat konsumen akhir dan harga di tingkat produsen.

\section{KESIMPULAN DAN SARAN}

\section{Kesimpulan}

Berdasarkan hasil penelitian dan pembahasan, maka dapat diambil beberapa kesimpulan sebagai berikut: Pemasaran kopi cap Lereng Tancak Kembar di Desa Andungsari Kecamatan Pakem Kabupaten Bondowoso meliputi 4 saluran pemasaran yang terdiri dari 2 saluran untuk kopi jenis arabika dan 2 saluran untuk kopi jenis robusta. Saluran pemasaran 1 kopi jenis arabika meliputi : agroindustri - sales - pedagang pengecer - konsumen akhir. Saluran pemasaran 2 kopi jenis arabika meliputi: agroindustri - pedagang pengecer - konsumen akhir. Saluran pemasaran 1 kopi jenis robusta meliputi: agroindustri - sales - pedagang pengecer - konsumen akhir. Saluran pemasaran 2 kopi jenis robusta meliputi: agroindustri pedagang pengecer - konsumen akhir. Margin pemasaran kopi arabika cap Lereng Tancak Kembar pada saluran 1 adalah sebesar Rp. $86.660,00$ per kilogram kopi arabika. Margin pemasaran kopi cap Lereng Tancak Kembar pada saluran 2 adalah sebesar Rp. 53.330,00 per kilogram kopi arabika. Marjin pemasaran kopi robusta cap Lereng Tancak Kembar pada saluran 1 sebesar Rp. 100.000,00 per kilogram kopi robusta. Serta marjin pemasaran kopi cap Lereng Tancak Kembar pada saluran 2 sebesar Rp. 85.000,00 per kilogram kopi robusta.

\section{Saran}

Sebaiknya pihak agroindustri Lereng Tancak Kembar lebih mamasarkan kopi arabika dan robsuta pada saluran 2, karena margin pemasarannya masing-masing lebih kecil dibandingkan dengan saluran saluran 1 .

\section{DAFTAR PUSTAKA}

Ali, Talumingan, Pangemanan, dan Kumaat. 2015. Efisiensi Pemasaran Bawang Merah di Desa Tonsewer Kecamatan Tompaso Barat Kabupaten Minahasa. Jurnal ASE, 11 (2A), 21-32.

Badan Pusat Statistik (BPS) Kabupaten Bondowoso. 2016. Industri Kecil, Tenaga Kerja dan Produksi Menurut Sub Sektor Industri 2015. Katalog BPS Kabupaten Bondowoso.

Dyanasari, Wahyunindyawati, Asnah, dan Kasijadi, F. 2010. Pendekatan S-C-P pada Pengukuran Efisiensi Pemasaran Bawang Merah di Kabupaten Probolinggo. Buana Sains, 10(1), 57-66.

Nazir, Moh. 2014. Metode Penelitian. Bogor: Ghalia Indonesia.

Rahardjo, Pudji. 2012. KOPI: Panduan Budi Daya dan Pengolahan Kopi Arabika dan Robusta. Jakarta: Penebar Swadaya.

Soekartawi. 2001. Seminar Nasional Aplikasi Teknologi Informasi. Yogyakarta: SNATI.

Soetriono. 2006. Daya Saing Pertanian dalam Tinjauan Analisis. Malang: Bayumedia.

Sugiarti, Sri. 2010. Analisis Pemasaran Kopi di Kecamatan Bermani Ulu Raya Kabupaten Rejang Lebong. AGRISEP, 9 (2), 130-136.

Suherman, T., Elys, F., dan Fuad, H. 2011. Analisis Pemasaran Garam Rakyat (Studi Kasus Desa Kertasada, Kecamatan Kalianget, Kabupaten Sumenep). Embrio, 8 (2), 73-81.

Wuwung, S. C. 2013. Manajemen Pemasaran Produk Cengkeh pada Desa Wawona Minahasa Selatan. EMBA, 1 (3), 230-238 